\title{
Prehospital emergency anaesthesia: an updated survey of UK practice with emphasis on the role of standardisation and checklists
}

\author{
Mark R Burgess, ${ }^{1,2}$ Kate Crewdson, ${ }^{3,4}$ David J Lockey, ${ }^{2,4}$ Zane B Perkins ${ }^{2,4}$
}

\begin{abstract}
Additional material is published online only. To view please visit the journal online (http://dx.doi.org/10.1136/ emermed-2017-206592).

${ }^{1}$ Department of Anaesthesia and Critical Care, Royal Cornwall Hospitals, TRURO, UK ${ }^{2}$ Centre for Trauma Sciences, Queen Mary University of London, London, UK

${ }^{3}$ Department of Anaesthesia, North Bristol NHS Trust, Bristol, UK

${ }^{4}$ London's Air Ambulance, London, UK
\end{abstract}

Correspondence to Dr Mark R Burgess, Department of Anaesthesia and Critical Care, Royal Cornwall Hospital, Truro TR1 3LQ, UK; mda05mtb@gmail.com

Received 11 January 2017 Revised 5 March 2018 Accepted 17 March 2018 Published Online First 24 May 2018
ABSTRACT

Introduction Prehospital emergency anaesthesia

(PHEA or 'prehospital rapid sequence intubation') is a high-risk procedure. Standard operating procedures (SOPs) and checklists within healthcare systems have been demonstrated to reduce human error and improve patient safety. We aimed to describe the current practice of PHEA in the UK, determine the use of checklists for PHEA and describe the content, format and layout of any such checklists currently used in the UK.

Method A survey of UK prehospital teams was conducted to establish the incidence and conduct of PHEA practice. Results were grouped into systems delivering a high volume of PHEA per year ( $>50$ PHEAs) and low volume ( $\leq 50$ PHEAs per annum). Standard and 'crash' (immediate) induction checklists were reviewed for length, content and layout.

Results 59 UK physician-led prehospital services were identified of which 43 (74\%) participated. Thirty services (70\%) provide PHEA and perform approximately 1629 PHEAs annually. Ten 'high volume' services deliver 84\% of PHEAs per year with PHEA being performed on a median of $11 \%$ of active missions. The most common indication for PHEA was trauma. 25 of the 30 services $(83 \%)$ used a PHEA checklist prior to induction of anaesthesia and $24(80 \%)$ had an SOP for the procedure. $19(76 \%)$ of the 'standard' checklists and $5(50 \%)$ of the 'crash' induction checklists used were analysed. On average, standard checklists contained 169 (range: 52-286) words and 41 (range: 28-70) individual checks. The style and language complexity varied significantly between different checklists.

Conclusion PHEA is now performed commonly in the UK. The use of checklists for PHEA is relatively common among prehospital systems delivering this intervention. Care must be taken to limit checklist length and to use simple, unambiguous language in order to maximise the safety of this high-risk intervention.

\section{INTRODUCTION}

Linked

- http://dx.doi.org/10.1136/ emermed-2018-207782

Check for updates

To cite: Burgess MR,

Crewdson K, Lockey DJ,

et al. Emerg Med J

2018:35:532-537
A subset of patients may require tracheal intubation prior to hospital arrival to ensure a patent airway, adequate oxygenation and optimal ventilation. ${ }^{1}$ The recommended method for prehospital emergency anaesthesia (PHEA or 'prehospital rapid sequence intubation') is one using hypnotic drugs and muscle relaxation, followed by oral tracheal intubation. ${ }^{23}$ While potentially life-saving, PHEA is a complex procedure with significant risks of considerable, unnecessary, harm. ${ }^{45}$

\section{Key messages}

What is already known on this subject

- Prehospital emergency anaesthesia (PHEA) is a high-risk procedure for which the highest clinical standards should be expected.

- Standard operating procedures and checklists are widely used throughout prehospital care to increase patient safety.

- Previous research has shown that PHEA is performed widely in the UK but did not specifically examine the role and content of checklists.

What this study adds

- PHEA is performed commonly in the UK but is not available 24 hours a day across the entire country.

- PHEA is most often performed by a small number of experienced teams with high case loads.

- Checklists for PHEA are used commonly, although not universally, to enhance safety.

- The word counts, number of checks, language style and structure of these checklists vary widely.

A robust governance system for PHEA should improve patient safety and the overall benefit of intervention. ${ }^{2}$ Standardisation of the procedure ${ }^{6}$ through the use of checklists and standard operating procedures (SOPs) can improve the safety and effectiveness of PHEA. ${ }^{7}$ The purpose of a checklist is to improve the performance of a complex procedure by providing a reminder of the most critical and important steps. ${ }^{8}$ The Association of Anaethetists of Great Britain and Ireland recommend that PHEA techniques should be straightforward, reproducible and supported by the use of checklists. ${ }^{2}$ Furthermore, the 'National Audit Project - 4' recommended the implementation of departmental guidelines and preintubation checklists for emergency anaesthesia outside the operating theatre setting. ${ }^{9}$

It is currently unclear how often PHEA is performed in the UK and to what extent checklists are used to support these procedures. The aim of this study was to describe the current practice of PHEA in the UK, determine the use of checklists for PHEA and describe the content, format and layout of these safety tools. 


\section{METHODS}

An online survey was designed with questions relating to the incidence of PHEA, and the use of and governance structures surrounding PHEA SOPs and checklists. Survey content was informed by expert knowledge and relevant literature, ${ }^{10} 11$ and was piloted with clinicians experienced in PHEA.

\section{Study population}

PHEA may only be performed by a physician in the UK. Prehospital services that include a physician were identified from those providers registered with the British Association of Immediate Care Services (BASICS) ${ }^{12}$ and UK Helicopter Emergency Medical Services (HEMS). ${ }^{13}$ Three prehospital teams who operate from an ED but who are not affiliated with either a BASICS or HEMS service were identified in Scotland (personal communication with an active prehospital clinician in Scotland, March 2014). Between March 2014 and May 2014, the lead clinicians from each service were invited to participate by email or post and were also asked to provide a copy of preinduction checklists used by their service. Reminder emails were sent weekly for 4 weeks, after which a telephone call was made. If no response was then received, we deemed that service had declined to participate. All data included in this study was returned by 30 May 2014.

\section{Data collection and definitions}

The full online questionnaire is available in online supplementary appendix A. Services were grouped into those performing PHEA > 50 times per annum (high-volume services) and those performing PHEA $\leq 50$ times per annum (low-volume services). The use of 50 PHEAs performed per annum to demarcate the low and high-volume services was largely arbitrary but does equate approximately to one procedure per week which we feel is a reasonable frequency to maintain individual and team competence in PHEA. The format, structure, background colour, text and language style of both the 'standard' and 'crash-induction' checklists were compared. The total number of checks, the frequency of specific checks and the total word counts were counted. Each new piece of information was counted as a separate check (eg, 'BP monitor on cycle and baseline BP seen' $=$ two checks). Observations on the differences in language style or sentence complexity were made by the main author for illustrative purposes only.

\section{Data analysis}

For both the questionnaire responses and checklist analysis, data were recorded on a spreadsheet (Microsoft Excel) prior to analysis. Statistical analyses were performed using Prism V.6.0 (GraphPad) software. Histogram plots were used to test for normality. Categorical data are reported as frequency (n) and $\%$, and numerical data as median with range. Fischer's exact test was used to compare categorical data and Mann-Whitney U test to compare numerical data. A two-tailed $\mathrm{p}$ value of $<0.05$ was considered significant.

\section{RESULTS}

Fifty-seven services that provide physician-based prehospital care in the UK were identified. These comprised 19 HEMS, 35 BASICS and 3 ED-based services. Two HEMS organisations combine operational data for clinical governance purposes and were thus considered as one service. We successfully contacted 54 (96\%) services, of which 43 (79\%) participated in the survey. . Included in final data analysis were 17 (94\%) HEMS services, 23 (66\%) BASICS services and 3 (100\%) ED-based services.

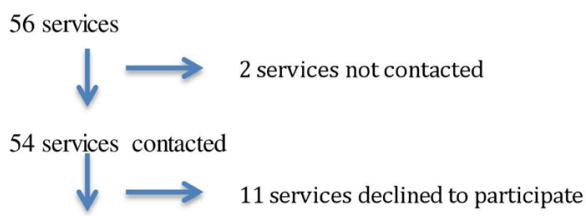

43 services participated

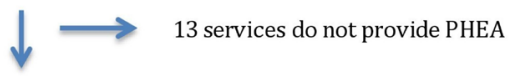

30 services provide PHEA

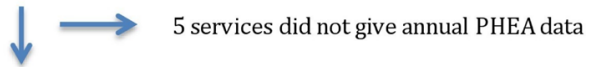

25 services gave annual data for PHEAs performed

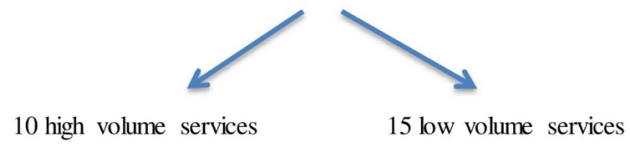

Figure 1 Flow chart showing number of services contacted, number who responded, the number who provide prehospital emergency anaesthesia (PHEA) and the number who provided annual PHEA data.

\section{Prehospital emergency anaesthesia}

In total, $30(70 \%)$ of the 43 services that responded had the capability to provide PHEA (17 HEMS, 10 BASICS, 3 ED-based services). Data for number of PHEAs performed were received from $25(83 \%)$ of these services (figure 1). Together, these 25 services perform approximately 1629 PHEA procedures per year at a (median 32, range: 0-400, figure 2).

In total, 10 services perform $>50$ PHEA procedures per year (high volume), 15 services performing $<50$ per year (low volume) and 5 services failed to submit this data. The 10 highvolume services, who were all HEMS services, perform approximately 84\% (1361 procedures) of all PHEA procedures per year. Eight $(27 \%)$ services have the ability to deliver PHEA throughout any 24-hour period (four high-volume and four low-volume services) while three (10\%) services can deliver the procedure during daylight hours only. A greater proportion of patients assessed and treated by high-volume services underwent PHEA compared with those seen by low-volume services (11.9\% vs 3.2\%; OR 4.7 (95\% CI 4.1 to 5.3); $\mathrm{P}<0.0001$ ). In both groups, the most common indication for PHEA was trauma (table 1).

\section{Checklist utilisation}

Of the 30 services that provide PHEA, the use of a preinduction checklist is mandatory in 23 services (10 high-volume and 13 low-volume services) and optional in 2 low-volume services. Five low-volume services do not have a PHEA checklist. All checklists are designed in a 'read-confirm' (or 'challenge-response') format. Two services purposefully vary the order of the individual checks over time. All 10 high-volume services use a checklist as part of a formal SOP for PHEA, while 14 (70\%) of low-volume services have such an SOP for PHEA.

For patients with impending cardiorespiratory arrest, 10 services (7 high-volume, 3 low-volume) use a separate, abbreviated preinduction checklist, 11 services (2 high-volume, 9 low-volume) use their standard checklist and 4 services (1 highvolume, 3 low-volume) waive the need to use a checklist in these situations (table 2). 


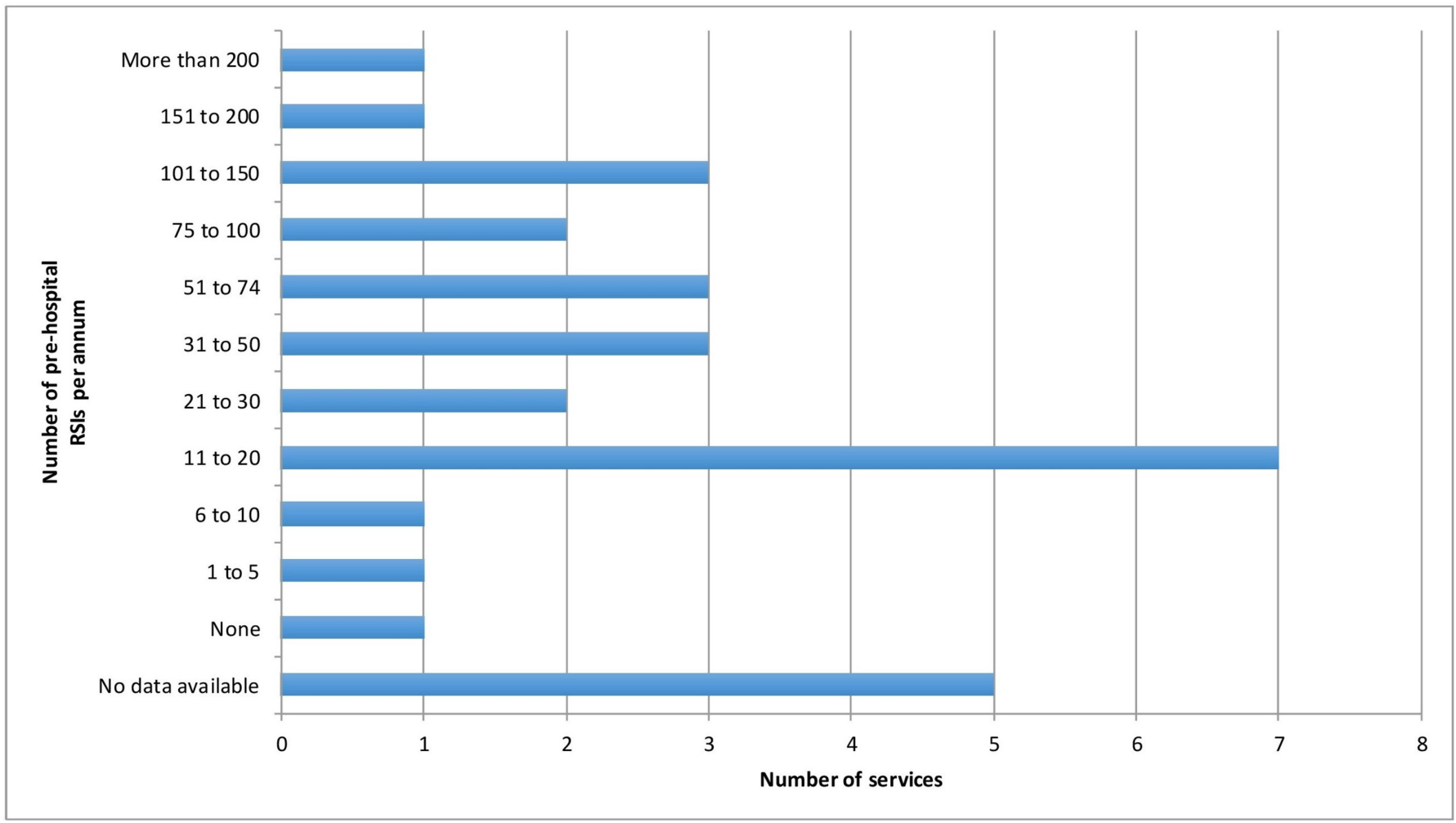

Figure 2 Number of times prehospital PHEAs are performed each year by UK prehospital care teams. RSIs and PHEAs, prehospital emergency anaestesia.

\section{Checklist development and governance}

Of the 25 services that use preinduction checklists, $19(76 \%)$ regularly employ training methods such as simulation or group discussion to enhance familiarity with the equipment and protocols for PHEA. In addition, 10 services (40\%) routinely audit clinical compliance with the use of checklists. All services review and/or revise the content and layout of their preinduction checklists, with 11 services (44\%) routinely seeking feedback from clinicians with regards to checklist length, content, layout and logistics of utilisation. The methods used to develop the checklists are shown in online supplementary appendix B.

\section{CHECKLIST ANALYSIS}

Nineteen (76\%) 'standard' checklists and five (50\%) crash-induction checklists were provided for analysis. Also, 16 (84\%)

\begin{tabular}{|c|c|c|}
\hline & \multicolumn{2}{|c|}{ Prehospital service } \\
\hline & High volume & Low volume \\
\hline Number of services & 10 & $15^{*}$ \\
\hline Annual case load (median) & 975 (564-1800) & $400(76-2500)$ \\
\hline PHEA per year (median) & $109(65-400)$ & $16(0-40)$ \\
\hline PHEA rate (\%) & $11.9(5-32)$ & $3.2(0-16)$ \\
\hline $\begin{array}{l}\text { Proportion of PHEA } \\
\text { performed for trauma } \\
\text { indications (\%) }\end{array}$ & $80.6(51-100)$ & $78.6(63-100) \dagger$ \\
\hline
\end{tabular}

Data presented as median (range) or \% (range) as indicated.

*Data displayed for those services that supplied PHEA data only.

tData displayed for 14 low-volume services.

PHEA, prehospital emergency anaesthesia. 'standard' checklists were printed on a single sheet of paper and $12(63 \%)$ featured black letters on a single-colour background. Thirteen checklists (68\%) were divided into distinct sections (eg, equipment, drugs) and six (32\%) consisted of a list of continuous checks.

'Crash' PHEA checklists were either printed on a separate page (four of five) or incorporated into the 'standard' checklist with the specific checks highlighted in colour (one of five). Word and number of checks counts are shown in table 2. Crash-induction checklists contained a median of 16 (range: 15-17) words and

Table 2 PHEA checklists in the UK; utilisation of standard and 'crash' induction checklists, total word counts and number of checks required, stratified for high-volume and low-volume services

\begin{tabular}{lcc}
\hline & \multicolumn{2}{c}{ Prehospital services $(\mathbf{n}=30)$} \\
\cline { 2 - 3 } & High volume & Low volume* \\
\hline SOP for PHEA & $10(100 \%)$ & $11(70 \%)$ \\
PHEA checklist use mandatory & $10(100 \%)$ & $13(65 \%)$ \\
PHEA checklist optional & $0(0 \%)$ & $2(10 \%)$ \\
PHEA checklist not used & $0(0 \%)$ & $5(25 \%)$ \\
Separate checklist for peri-arrest patients & $7(70 \%)$ & $3(15 \%)$ \\
Same PHEA used for all patients & $2(20 \%)$ & $9(45 \%)$ \\
No checklist used for peri-arrest patients & $1(10 \%)$ & $3(15 \%)$ \\
Median word count (standard checklist) & 172 & 129 \\
$\begin{array}{l}\text { Median number of checks (standard } \\
\text { checklist) }\end{array}$ & 41 & 39 \\
\hline
\end{tabular}

Data presented as number (\%) or median as stated.

*Number of low-volume services identified=15 (data on checklist/SOP usage also included for those five services not providing number of PHEAs performed).

PHEA, prehospital emergency anaesthesia; SOP, standard operating procedure. 
Table 3 Specific content analysis for 19 'standard' prehospital emergency anaesthesia (PHEA) checklists used in the UK

\begin{tabular}{|c|c|c|}
\hline Safety check & $\begin{array}{l}\text { Check } \\
\text { included? }\end{array}$ & Other comments RE-specific checks \\
\hline \multicolumn{3}{|l|}{ Optimisation of patient /conditions } \\
\hline Plan for difficult/failed airway verbalised? & $8(42 \%)$ & $\begin{array}{l}\text { Reminder to state difficult airway plan } n=1 \\
\text { Reminder to verbalise predicted difficult airway } n=1\end{array}$ \\
\hline Patient position (eg, trolley at correct height)? & $3(16 \%)$ & \\
\hline Patient physiology & $8(42 \%)$ & $\begin{array}{l}\text { Reminder to 'optimise pre-oxygenation' } n=1 \\
\text { Check that 'pre-oxygenation' occurs } n=8\end{array}$ \\
\hline Reminder to consider if thoracostomy required? & $5(26 \%)$ & \\
\hline \multicolumn{3}{|l|}{ Standard equipment } \\
\hline Oxygen store check? & $15(79 \%)$ & Back-up $\mathrm{O}_{2}$ cylinder $\mathrm{n}=7$ \\
\hline Patient monitoring & $19(100 \%)$ & $\begin{array}{l}-\mathrm{BP} / \mathrm{O}_{2} \text { sats monitoring }=15 \\
\mathrm{BP} / \mathrm{O}_{2} \text { sats/continuous ECG } \mathrm{n}=6 \\
\text { Rapid cycling of BP measurement } \mathrm{n}=3 \\
\text { Check just stating for 'monitor' and/or 'baseline obs' } \mathrm{n}=4\end{array}$ \\
\hline Capnography available? & $18(95 \%)$ & $\begin{array}{l}\text { Verification of working capnopgraphy } n=1 \\
\text { Verification that capnography is 'ready/connected' } n=17\end{array}$ \\
\hline Stethoscope & $11(58 \%)$ & \\
\hline Suction available? & $19(100 \%)$ & $\begin{array}{l}\text { Verification of working suction } n=7 \\
\text { Reserve suction available } n=9\end{array}$ \\
\hline Nasal cannulae for apnoeic oxygenation? & $1(5 \%)$ & \\
\hline Portable ventilator? & $8(42 \%)$ & $\begin{array}{l}\text { Verification of working ventilator } n=1 \\
\text { Verification that ventilator settings checked } n=2\end{array}$ \\
\hline Circuit equipment? & $12(63 \%)$ & $\begin{array}{l}>\text { Filter/HME } n=12 \\
\text { Catheter mount } n=5\end{array}$ \\
\hline \multicolumn{3}{|l|}{ Airway equipment } \\
\hline Laryngoscope check? & $19(100 \%)$ & Verification of working bulb $\mathrm{n}=17$ \\
\hline Alternative laryngoscope available? & $10(53 \%)$ & \\
\hline Mention of tracheal tube? & $18(95 \%)$ & $\begin{array}{l}\text { Correct tube size selected } n=14 \\
\text { Verification of cuff working } n=14\end{array}$ \\
\hline Alternative tube available? & $12(63 \%)$ & \\
\hline Tube tie and/or holder & $17(89 \%)$ & \\
\hline Syringe for cuff & $15(79 \%)$ & \\
\hline Airway adjuncts (eg, oropharyngeal airway) & $15(79 \%)$ & \\
\hline Rescue/difficult airway kit available? & $18(95 \%)$ & $\begin{array}{l}\text { Specific supraglottic airway available } n=15 \\
\text { Airtraq device available } n=1\end{array}$ \\
\hline \multicolumn{3}{|l|}{ Intravenous access/drugs } \\
\hline Drugs? & $19(100 \%)$ & $\begin{array}{l}\text { Specific drug(s) dose chosen } n=13 \\
\text { Specific drug(s) volume chosen } n=3\end{array}$ \\
\hline Intravenous access & $19(100 \%)$ & $\begin{array}{l}-2 \text { intravenous lines cited } n=15 \\
\text { Verification that lines patent } n=14\end{array}$ \\
\hline Emergency/resuscitation drugs check? & $7(37 \%)$ & $\begin{array}{l}\text { Specific drug(s) mentioned } n=3 \\
\text { Drug class mentioned (eg, alpha agonist) } n=1\end{array}$ \\
\hline Maintenance of anaesthesia post-PHEA check & $6(32 \%)$ & Specific drugs mentioned $\mathrm{n}=0$ \\
\hline \multicolumn{3}{|l|}{ Team brief } \\
\hline Team brief check? & $19(100 \%)$ & $\begin{array}{l}\text { MILS briefed } n=12 \\
\text { Drug giver briefed } n=9 \\
\text { Cricoid pressure/airway assistant briefed } n=17\end{array}$ \\
\hline
\end{tabular}

Data presented as number of checklists that included specific check (\%).

HME, heat moisture exchange; MILS, manual inline stabilisation.

12 (range: 10-13) checks. Tables 3 and 4 show the individual checks included in the standard and crash-induction checklists.

\section{Style and language analysis}

The style and language used in individual checklists varied considerably. Some checklists use simple, brief phrases on separate lines for individual checks, while others use complex, full sentences covering a number of checks. While the majority of checklists used specific, closed questions that facilitate a 'read-confirm' format, a number of checklists included long, open-ended questions (table 5).

\section{DISCUSSION}

At least 30 prehospital services in the UK are able to deliver PHEA. Over $80 \%$ of the estimated 1600 PHEA procedures performed each year follow traumatic injury. Ten high-volume, high case load services perform the majority of these procedures. All high-volume and most low-volume services use a preinduction checklist for PHEA, and these checklists vary considerably in terms of length, content, format and language.

In 2009, Cowan et al showed that PHEA was provided by a similar proportion of UK services (66\%) to that reported in this study. ${ }^{14}$ Our data suggests that from 2009 to 2014 the number 
Table 4 Specific content analysis for the five 'immediate-induction' checklists analysed

\begin{tabular}{|c|c|c|}
\hline \multirow[b]{2}{*}{ Safety check } & \multicolumn{2}{|c|}{ Is a check of this item included? } \\
\hline & Yes & Other comments \\
\hline Oxygen & $4(80 \%)$ & \\
\hline Tracheal tube & $4(80 \%)$ & $\begin{array}{l}\text { 'Cuff tested' } n=2 \\
\text { Specific size stated } n=3\end{array}$ \\
\hline Intubating bougie & $5(100 \%)$ & \\
\hline Suction & $4(80 \%)$ & Check to verify working $n=1$ \\
\hline Laryngoscope & $5(100 \%)$ & $\begin{array}{l}\text { ' } 2 \text { available' } n=1 \\
\text { Check to verify that bulb is working } n=1\end{array}$ \\
\hline Syringe for cuff & $4(80 \%)$ & \\
\hline Capnography & $5(100 \%)$ & $\begin{array}{l}\text { Check to verify that capnography working } \\
\mathrm{n}=0\end{array}$ \\
\hline Drugs & $4(80 \%)$ & $\begin{array}{l}\text { Specific drug(s) dose stated } n=1 \\
\text { Post-PHEA drugs mentioned } n=1\end{array}$ \\
\hline
\end{tabular}

PHEA, prehospital emergency anaesthesia.

of services performing $>50$ PHEAs per annum has doubled from 5 to 10 . However, the authors had identified different numbers of HEMS and BASICS services, and thus direct data comparisons cannot be made. No previous data reporting the availability of PHEA in a given 24-hour period were identified, and we showed that only one-quarter of services could provide this service 24 hours per day. However, the implementation of subspecialty training in prehospital emergency medicine in $2012^{15}$ may increase its availability. Physicians working in low-volume services may conduct PHEA infrequently. Given the correlation between the frequency of ongoing experience and predicted difficult intubation ${ }^{16}$ and first-pass success, ${ }^{17}$ such physicians may need to supplement such experience with time delivering in-hospital anaesthesia.

Furthermore, between 2009 and 2014, the proportion of UK services using a preinduction checklist has risen from $65 \%$ to $83 \%$ overall. ${ }^{14}$ PHEA is a complex procedure, and these patients are often severely injured and severely physiologically deranged. They should, therefore, be considered to be at high risk of complications. Moreover, human memory recall is finite and will be further impaired in cognitively overwhelming and challenging environments. A well-designed checklist should remind

Table 5 Examples of differences in style and language complexity between different prehospital prehospital emergency anaesthesia (PHEA) checklists used in the UK

\begin{tabular}{|c|c|c|}
\hline & $\begin{array}{l}\text { Bullet point checks/ } \\
\text { closed questions }\end{array}$ & $\begin{array}{l}\text { Sentences containing multiple } \\
\text { checks or as open questions }\end{array}$ \\
\hline Equipment/drugs & $\begin{array}{l}\text { 'Bougie and KY' } \\
\text { '20 mL syringe' } \\
\text { 'Monitor visible' } \\
\text { 'Suction' } \\
\text { 'Surgical airway } \\
\text { available'? } \\
\text { 'Two working IVs'? }\end{array}$ & $\begin{array}{l}\text { 'Lifepak } 12 \text { from aircraft attached to } \\
\text { patient and visible with continuous } \\
\mathrm{ECG} \mathrm{SaO}_{2}, \mathrm{NIBP} \text { (on automatic cycle } \\
\text { repeating every } 1 \text { min) and } \mathrm{CO}_{2} \\
\text { ready'. } \\
\text { 'Intubation agent drawn up and } \\
\text { labelled, dose selected'. } \\
\text { 'Suction develops vacuum, rigid } \\
\text { and fine tubes. Under patients right } \\
\text { shoulder'. } \\
\text { 'Is there any additional rescue airway } \\
\text { equipment needed?' } \\
\text { 'Is there adequate vascular access?' }\end{array}$ \\
\hline Patient positioning & $\begin{array}{l}\text { 'Patient position } \\
\text { optimised?' }\end{array}$ & $\begin{array}{l}\text { ' } 360^{\circ} \text { access, on stretcher, good } \\
\text { lighting, cover, check other hazards/ } \\
\text { nightfall' }\end{array}$ \\
\hline
\end{tabular}

clinicians of the standard equipment, monitoring and drugs required to improve procedural safety and so compensate for human fallibility.

All services use either simulation, didactic lectures, written information or a combination of methods to improve familiarity with SOPs and preinduction checklists. In particular, patient simulation or moulage is widely recommended as a technique for both familiarising clinicians with medical checklists and to facilitate checklist revision. ${ }^{10}{ }^{11}$ All services revise their checklists but fewer than half do so regularly or seek feedback from clinicians. This is vital to ensure they are consistent with current best practice. ${ }^{10}$

From a qualitative study involving "high-reliability organisations', Thomassen et al concluded that limiting the length of a checklist is crucial for feasibility and practicality. ${ }^{10}$ Equally, Hales et al recommended that the length of a medical checklist should be limited so as to not interfere with the administration of patient care. ${ }^{12}$ While the aim is to reduce the cognitive demand on the user, a longer checklist may either unnecessarily delay an intervention or cause 'checklist fatigue' to occur. Consequently, the user may skip over important steps to complete the checklist sooner. One strategy sometimes used in aviation to mitigate against 'automaticity' (where checks are performed with limited attention to the detail) is to vary the order of the checks themselves $^{18}$; only a few UK prehospital services do this.

Critically ill patients may require immediate definitive airway management, permitting brief preparation time. Almost half of the services require their clinicians to complete a standard checklist, containing an average of 38 checks, regardless of clinical urgency. Mandatory, laborious checklists in a peri-arrest scenario may cause the omission or rushing of critical checks, resulting in unnecessary harm.

Hales et al recommended that checklist writers should consider the intended setting where it will be used when determining checklist content and structure. ${ }^{11}$ PHEA checklists that include long, open questions may ultimately present a greater cognitive burden than that which the checklist was intended to reduce. Some authors advocate that medical checklists should use simple, short unambiguous checks, ${ }^{19}$ although the evidence supporting this over more elaborate, multifaceted checks is lacking.

\section{Recommendations for prehospital PHEA safety checklists}

Based on the clinical experience of the authors, the available literature and the current PHEA checklists in use, we make the following recommendations:

- Regular training with all clinical staff who use PHEA checklists, preferably using simulation.

- Regular review of the length, content and format of the checklist using feedback from the clinicians, formerly and routinely.

- Limit the length of checklists to the absolute minimum, excluding any non-vital information, ensuring that each check increases the safety of the procedure.

- Keep language simple, direct and unambiguous, avoiding complex and challenging questions.

\section{Study limitations}

We attempted to minimise the inherent bias of survey studies by extensively piloting the survey among senior clinicians involved in the delivery of PHEA. The incidence of PHEA in the UK may be higher due to non-responders and missing data. The majority of non-responders and those who provided inadequate data were BASICS services who we believe tend to 
be low-volume services and may be less likely to use checklists. This is also the reason for their inclusion in the analysis of checklist usage and the checklists themselves divided into high-volume and low-volume services.

\section{CONCLUSION}

This was a nationwide survey of prehospital teams with a good response rate. PHEA is performed frequently in the UK, and checklists are being increasingly used by the majority of UK prehospital teams to reduce human error and improve patient safety. A small number of high-volume teams perform the majority or PHEAs in the UK and are more likely to use a PHEA checklist. The length, content, layout and language style varied considerably across the checklists analysed. While we have made recommendations on their content, style and governance structure, there must be scope to make each PHEA checklist relevant and appropriate to the service in which it will be used.

Contributors MRB conceived and designed the study, devised and piloted the survey questionnaire, collected and analysed the data and wrote the manuscript. ZBP assisted with study design, the survey questionnaire and data analysis and edited the manuscript. KC and DJL assisted with data analysis and edited the manuscript. All authors approved the final manuscript.

Funding The authors have not declared a specific grant for this research from any funding agency in the public, commercial or not-for-profit sectors.

Competing interests None declared.

Patient consent Not required.

Ethics approval The study protocol was reviewed by the Research Ethic Committee for Queen Mary, University of London, who deemed full ethics approval to be unnecessary.

Provenance and peer review Not commissioned; externally peer reviewed.

(c) Article author(s) (or their employer(s) unless otherwise stated in the text of the article) 2018. All rights reserved. No commercial use is permitted unless otherwise expressly granted.

\section{REFERENCES}

1 Lockey DJ, Healey B, Crewdson K, et al. Advanced airway management is necessary in prehospital trauma patients. Br J Anaesth 2015;114:657-62.
2 Lockey DJ, Crewdson K, Davies G, et al. AAGBI: Safer pre-hospital anaesthesia 2017: association of anaesthetists of Great Britain and Ireland. Anaesthesia 2017;72:379-90.

3 National institute for health and care excellence. https://www.nice.org.uk/guidance/ ng39 (accessed Mar 2017).

4 Davis DP, Dunford JV, Poste JC, et al. The impact of hypoxia and hyperventilation on outcome after paramedic rapid sequence intubation of severely head-injured patients. J Trauma 2004;57:1-10.

5 Wirtz DD, Ortiz C, Newman DH, et al. Unrecognized misplacement of endotracheal tubes by ground prehospital providers. Prehosp Emerg Care 2007:11:213-8.

6 Sherren PB, Tricklebank S, Glover G. Development of a standard operating procedure and checklist for rapid sequence induction in the critically ill. Scand J Trauma Resusc Emerg Med 2014;22:41.

7 Lyon RM, Perkins ZB, Chatterjee D, et al. Significant modification of traditional rapid sequence induction improves safety and effectiveness of pre-hospital trauma anaesthesia. Crit Care 2015;19:134.

8 Gawande A. The checklist manifesto: how to get things right. New York: Metropolitan Books, 2010.

9 Cook TM, Woodall N, Harper J, et al. Major complications of airway management in the UK: results of the fourth national audit project of the royal college of anaesthetists and the difficult airway society. Part 2: intensive care and emergency departments. $\mathrm{Br}$ J Anaesth 2011;106:632-42.

10 Thomassen $\varnothing$, Espeland A, Søfteland E, et al. Implementation of checklists in health care; learning from high-reliability organisations. Scand I Trauma Resusc Emerg Med 2011;19:53.

11 Hales B, Terblanche M, Fowler R, et al. Development of medical checklists for improved quality of patient care. Int I Qual Health Care 2008;20:22-30.

12 British association for immediate care. www.basics.org.uk (accessed 1 Mar 2017).

13 Helicopter emergency medical services UK. www.uk-hems.uk/ (accessed $1 \mathrm{Mar}$ 2017).

14 Cowan GM, Burton F, Newton A. Prehospital anaesthesia: a survey of current practice in the UK. Emerg Med J 2012;29:136-40.

15 Intercollegiate Board for Training in Pre-Hospital Emergency Medicine. http://www. ibtphem.org.uk (accessed 1 Mar 2017)

16 Breckwoldt J, Klemstein S, Brunne B, et al. Expertise in prehospital endotracheal intubation by emergency medicine physicians-Comparing 'proficient performers' and 'experts'. Resuscitation 2012;83:434-9.

17 Harris T, Lockey D. Success in physician prehospital rapid sequence intubation: what is the effect of base speciality and length of anaesthetic training? Emerg Med J 2011;28:225-9.

18 Barshi I, Healy AF. Checklist procedures and the cost of automaticity. Mem Cognit 1993;21:496-505.

19 Winters BD, Gurses AP, Lehmann $\mathrm{H}$, et al. Clinical review: checklists - translating evidence into practice. Crit Care 2009;13:210. 